\title{
Pojęcie natury ludzkiej w nauce i teologii *
}

\section{Wprowadzenie}

Moim głównym celem jest przyczynienie się do lepszego zrozumienia, jak religia i nauka ${ }^{* *}$ mogą wzajemnie wpływać na swoją treść. Jednym z powodów, dla których chrześcijanie utrzymują religię i naukę w separacji, jest obawa, że zmiany w naukowym rozumieniu przyrody wymuszą zmiany w przekonaniach religijnych. Wielu chrześcijan, chcąc złagodzić tę obawę, wyklucza istnienie oddziaływania między tymi dziedzinami, redukując jego złożoność. Naukę oraz religię sprowadza się na przykład do odrębnych dziedzin wiedzy, w których obowiązują ich własne, swoiste twierdzenia. Twierdzi się bowiem, że relacje zachodzące pomiędzy zbiorami twierdzeń ograniczają się do relacji jedynie logicznych. Jednakże zgodnie $\mathrm{z}$ teorią typów logicznych ${ }^{1}$ pomiędzy religią a nauką nie mogą zachodzić żadne relacje logiczne, jeśli tę pierwszą rozumie się jako pozalogiczny sposób funkcjonowania człowieka zwany wiarą, drugą zaś - jako logiczny sposób funkcjonowania. Niemniej udało się zidentyfikować przynajmniej jedną relację logiczną między religią a nauką, ${ }^{2}$ a wywierały one na siebie

"Jitse M. van DER MeEr, „The Concept of Human Nature in Science and Theology”, Studies in Science and Theology 1997, vol. 3, s. 187-192. Za zgodą Autora i Redakcji z języka angielskiego przełoży: Radosław Plato.

** (Przyp. tłum.) W tekście termin ,nauka” rozumiany jest w anglosaskim znaczeniu ,science" - jako nauki empiryczne.

${ }^{1}$ Por. Bertrand Russell, Principles of Mathematics, 2nd ed., W.W. Norton \& Company, Inc., New York 1903.

${ }^{2}$ Por. Amos Funkenstein, Theology and the Scientific Imagination from the Middle Ages to the Seventeenth Century, Princeton University Press, Princeton 1986, s. 76-77. Logiczna natura tej relacji jest otwarta na interpretacje. Por. w tej sprawie: Gerd Buchdahl, Metaphysics and the 
wpływ także na inne sposoby. ${ }^{3}$ Moja propozycja pozwala na wyjaśnienie tych sposobów oddziaływania dzięki zastapieniu jednowymiarowych logicznych koncepcji poznania, takich jak syntaktyczne oraz semantyczne ujęcia teorii, ${ }^{4}$ wielowymiarową koncepcją poznania. Rozpocznę od osadzenia oddziaływań pomiędzy religią a nauką w naturze ludzkiej, ponieważ wyłącznie ludzie stoją w relacji zarówno do Boga, jak i przyrody. Następnie zastosuję analizę poziomów organizacji do natury ludzkiej.

\section{Poziomy organizacji}

Struktury poziomów to warstwy struktur epistemologicznych używane do wyznaczania poziomów przedmiotów i zjawisk wedle określonego kryterium. Wspomnę jedynie o zagnieżdżonym oraz modalnym typie struktury poziomów. Podstawą zagnieżdżonej struktury poziomów jest fizyczna relacja części do całości: części definiuje się jako przedmioty fizycznie zawierające się w całościach. W rezultacie mamy do czynienia ze Wszechświatem przypominającym pojemnik, w którym elementami składowymi cząsteczek są atomy, organizmów — komórki, a Wszechświata — galaktyki. Natomiast modalna struktura poziomów klasyfikuje przedmioty i zjawiska na podstawie liczby nieredukowalnych sposobów ich funkcjonowania. Na przykład zarówno kryształy, jak i zwierzęta funkcjonują w sposób przestrzenny, liczbowy, kinematyczny i chemiczny. Funkcjonują one w sposób liczbowy w tym sensie, że te pierwsze mają cztery strony, a drugie - cztery nogi. Jednakże zwierzęta funkcjonują także w sposób biotyczny i percepcyjny. Ludzie funkcjonują we wszystkie wymienione sposoby, ale także w sposób obserwacyjny, emocjonalny, logiczny, wyobrażeniowy oraz religijny. $\mathrm{Z}$ epistemologicznego punktu widzenia poziom modalny jest przeto pewnym zbiorem praw, teorii i pojęć opisujących pewien nieredukowalny sposób funkcjonowania. Natomiast z perspektywy ontologicznej niższy po-

Philosophy of Science. The Classical Origins: Descartes to Kant, The MIT Press, Cambridge, Massachusetts 1969, s. 147-180.

${ }^{3}$ Por. John Hedley Brooke, Science and Religion. Some Historical Perspectives, Cambridge Studies in the History of Science, Cambridge University Press, Cambridge 1991.

${ }^{4}$ Por. Frederick Suppe, The Semantic Conception of Theories and Scientific Realism, University of Illinois Press, Urbana 1989, s. 82, 84, 86, 270-271. 
ziom stanowi warunek konieczny, ale nie wystarczający istnienia kolejnego, wyższego poziomu.

Zastosowanie koncepcji poziomów organizacji do natury ludzkiej wymaga wyboru między zagnieżdżoną a modalną strukturą poziomów. Wybór ten dotyczy rzeczywistości Boga oraz możliwości zawierzenia Mu. Zjawiska mentalne i religijne nie są fizycznie zawarte $w$ zjawiskach materialnych ani tych ostatnich nie zawierają. Dlatego nie pasują do zagnieżdżonej struktury poziomów, chyba że jako epifenomeny. ${ }^{5}$ Istnienie Boga i nasza wiedza o tym stałyby się złudzeniami, które wyłaniają się z dynamiki materii. Przedmiot badań teologii zostałby zredukowany do doświadczeń religijnych i aktywności ludzkiej zinterpretowanych jako funkcje zjawisk biologicznych i psychologicznych. Nie można, rzecz jasna, pokładać nadziei w Bogu, który jest tylko złudzeniem. Jednakże do poziomów modalnych zalicza się istnienie niematerialnych rzeczywistości, takich jak Bóg. Poziomy te mieszczą także mentalne i duchowe sposoby funkcjonowania człowieka, nie sprowadzając ich do epifenomenów (umysłu) oraz konstruktów mentalnych (Boga, religii, umysłu, liczby i przestrzeni), jak w przypadku zagnieżdżonej struktury poziomów.

\section{Trzy typy oddzialywań pomiędzy religią a nauką}

Nieredukowalne sposoby funkcjonowania człowieka ujawniają się w odpowiadających sobie wymiarach relacji osoby do Boga oraz przyrody. Dwa spośród tych wymiarów to zawierzenie Bogu i poznanie. ${ }^{6}$ Poznanie prowadzi do przekonań pojęciowych dotyczących Boga oraz przyrody. Teologia i nauki empiryczne stanowią systematyczne i pogłębione próby poznania Boga i przyrody. W ten sposób objaśnione zostaje znaczenie terminów „religia” i „nauka”. Oddziaływanie pomiędzy religią a nauką rozumie się jako zachodzące pomiędzy (1) zawierzeniem Bogu (wiarą) a przekonaniami dotyczącymi Boga (teologią);

\footnotetext{
${ }^{5} \mathrm{Na}$ przykład w socjobiologii zagnieżdżenie pociąga za sobą analogię między atomami, genami oraz ludźmi. Analogii tej używa się w celu uzasadnienia zastosowania teoretycznej aparatury mechaniki kwantowej do opisu i wyjaśniania zjawisk społecznych. Jest to więc pewien fizykalny model rzeczywistości społecznej oraz religijnej.

${ }^{6}$ Por. M.C. Grant, „Faith and Belief”, The Iliff Review 1977, vol. 34, s. 21-27; Wilfred C. Sмітн, Faith and Belief, Princeton University Press, Princeton, New Jersey 1979.
} 
(b) zawierzeniem Bogu (wiarą) a przekonaniami dotyczącymi świata (nauką) oraz (c) przekonaniami dotyczącymi Boga (teologią) a przekonaniami dotyczącymi świata (nauką).

Jakie korzyści wynikają z przyjęcia, że zawierzenie Bogu i poznanie są odmiennymi sposobami, w jakie człowiek odnosi się do Boga i przyrody? Jakie korzyści płyną z powstałych tym samym trzech różnych trybów oddziaływania pomiędzy religią a nauką? Po pierwsze, antropologiczny przedmiot zainteresowania sugeruje, w jaki sposób przekonania dotyczące Boga i przyrody mogą wzajemnie wpływać na swoją treść. Korzyść ta związana jest z oddziaływaniem między poznawczym a twórczym poziomem funkcjonowania osoby. Ludzie poznają to, co nieznane, drogą twórczych porównań z tym, co już wiedzą. ${ }^{7}$ Wiąże się to z przeniesieniem znaczenia pomiędzy każdym znanym i nieznanym światem znaczeń. ${ }^{8}$ Gdy ludzie próbują zrozumieć przyrodę w kategoriach Boga i vice versa albo gdy Bóg objawia się w przyrodzie, to pomiędzy przekonaniami o Bogu a przekonaniami o przyrodzie powstają relacje znaczeniowe. Relacje takie obejmują użycie pojęć naukowych w znaczeniu religijnym, a także użycie pojęć religijnych w znaczeniu naukowym. Przykładowo, gdy Faraday wywnioskował jedność sił elektrycznych i magnetycznych $\mathrm{z}$ jedności trzech osób w Trójcy Świętej, znaczenie pojęcia religijnego zostało przeniesione do pojęcia fizycznego. ${ }^{9}$ Podobne przeniesienie znaczenia miało miejsce, gdy Kartezjusz

\footnotetext{
${ }^{7}$ Por. Michael A. Arbib and Mary B. Hesse, The Construction of Reality, Cambridge Studies in Philosophy, Cambridge University Press, Cambridge - New York 1986; Mary Gerhart and Allan M. Russell, Metaphoric Process: The Creation of Scientific and Religious Understanding, Texas University Press, Fort Worth 1984; Mary B. Hesse, „The Cognitive Claims of Metaphor", The Journal of Speculative Philosophy. New Series 1988, vol. 2, no. 1, s. 1-16; Nancy J. NerSessian, „Reasoning from Imagery and Analogy in Scientific Concept Formation”, w: Arthur Fine and Jarrett LePlin (eds.), Proceedings of the 1988 Biennial Meeting of the Philosophy of Science Association, vol. 1, East Lansing, Michigan 1988, s. 41-47; Nancy J. NERSESSIAN, „How Do Scientists Think? Capturing the Dynamics of Conceptual Change in Science”, w: Ronald N. Giere (ed.), Cognitive Models in Science, Minnesota Studies in the Philosophy of Science, vol. 15, University of Minnesota Press, Minneapolis 1992, s. 3-44.

${ }^{8}$ Relacje znaczeniowe między naukami empirycznymi a teologią stanowią szczególny przypadek relacji znaczeniowych pomiędzy dowolnymi dziedzinami wiedzy, takimi jak rozmaite dyscypliny naukowe, w których relacje te odgrywają pewną rolę w badaniach nad redukcją teorii.

${ }^{9}$ Por. Geoffrey N. CANToR, Michael Faraday, Sandemanian and Scientist. A Study of Science and Religion in the Nineteenth Century, Mcmillan, Basingstocke — London 1991.
} 
wyprowadził prawo bezwładności, a także ideę zachowania ilości ruchu z idei niezmienności Boga. ${ }^{10}$ Przeniesienie znaczenia może dotyczyć dowolnego przekonania religijnego, ponieważ dokonywanie twórczych porównań cechuje poznanie i wyobraźnię, nie religię. Przeniesienie takie wymaga jedynie podobieństw między przyrodą a bóstwem. ${ }^{11}$

Kiedy dochodzi do przeniesienia znaczenia między Bogiem a przyrodą, używa się pojęć nauki w znaczeniu religijnym, a pojęć religijnych — w naukowym. Oznacza to, że nośnikami znaczenia są raczej użytkownicy, a nie właściwości języka nauki. ${ }^{12}$ Druga korzyść, jakiej dostarcza to podejście, polega na tym, że ustala ono warunki istnienia relacji logicznych pomiędzy religią a nauką. Relacje logiczne nie mogą zachodzić pomiędzy zawierzeniem Bogu a przekonaniami pojęciowymi o przyrodzie, ponieważ stanowią one nieredukowalne sposoby funkcjonowania. Twierdzenia epistemologiczne nie wynikają z wiary $\mathrm{z}$ tego samego powodu, $\mathrm{z}$ jakiego twierdzenia obserwacyjne nie wynikają $\mathrm{z}$ obserwacji, należą one bowiem do odmiennych typów logicznych. Relacje logiczne mogą zachodzić wyłącznie między przekonaniami pojęciowymi, na przykład pomiędzy pojęciowymi przekonaniami o Bogu i przyrodzie, a i to wyłącznie, gdy są one wzajemnie powiązane. Przykładowo przekonanie, że Bóg jest święty, nie ma związku z przekonaniem, iż przyroda jest deterministyczna. Przekonanie, że przyroda jest nieciągła, najprawdopodobniej nie ma zaś żadnych kon-

\footnotetext{
${ }^{10}$ Por. przyp. 2.

${ }^{11}$ Przykładami takich podobieństw są identyfikowanie przyrody z bóstwami (animizm, panteizm) oraz przekonanie, że przyroda dostarcza wiedzy o bóstwie w taki sposób jak pogląd o podobieństwie mikrokosmosu i makrokosmosu. Za przykład tego drugiego przypadku niech posłuży pogląd starożytnych Greków o czerpaniu z natury pewnych wskazówek etycznych. Poglądy takie mogły prowadzić do przeniesienia znaczenia z nauki, która nie jest specyficzna dla chrześcijaństwa. Dla chrześcijaństwa charakterystyczne jest przeświadczenie, że Bóg mówi o sobie językiem przyrody (objawienie dostosowane), a chrześcijanie mówią o przyrodzie językiem Boga. To właśnie pozwala, by chrześcijańskie pojęcia religijne nabierały przyrodniczego znaczenia, zaś pojęcia naukowe - znaczenia religijnego.

${ }^{12}$ Por. Janet M. Soskice, Metaphor and Religious Language, Oxford University Press, Oxford 1985, s. 52. Rozszerzenie tego, co znane, na to, co nieznane, nazywam analogicznym, jeśli rozszerzenie to nie prowadzi do napięć poznawczych, zaś metaforycznym, jeśli do takich napięć prowadzi (por. Gerhart and Russell, Metaphoric Process..., s. 110,113; Soskice, Metaphor..., s. 64-66). Analogia i metafora pozwalają na przeniesienie znaczenia pomiędzy wiedzą o Bogu a wiedzą o przyrodzie.
} 
sekwencji dla przekonania, iż Bóg jest cierpliwy. Wzajemny związek istnieje, gdy ludzie myślą o Bogu w kategoriach przyrody, jak ma to miejsce w teologii naturalnej czy teologii procesu. Taki związek zachodzi także, gdy ludzie myślą o przyrodzie w kategoriach Boga, jak w przekonaniu, że przyroda jest deterministyczna, bo Bóg nie gra w kości. Wreszcie, wzajemny związek istnieje, gdy Bóg objawia się w przyrodzie, na przykład pod postacią słupa ognia czy wiatru, bądź jako Bóg Ojciec lub Pasterz. Uważam więc, że pojęcia religijne użyte w znaczeniu przyrodniczym mogą prowadzić do wniosków dotyczących przyrody. Tak samo pojęcia przyrodnicze użyte w znaczeniu religijnym mogą prowadzić do wniosków dotyczących Boga. ${ }^{13}$

Wynika z tego, że określonego słowa można użyć w rozmaitych znaczeniach. Wedle Mary Hesse ta zmienność znaczeniowa uniemożliwia zachodzenie logicznych relacji równoważności oraz wynikania, ,ponieważ znak słowny, który zmienia swoje «znaczenie» w zależności od czasu lub kontekstu, nie może stanowić elementu formalnego, który jest ponownie identyfikowalny i wymienny, gdziekolwiek pojawia się w obrębie danego systemu logicznego". ${ }^{14} \mathrm{~W}$ mojej opinii jest to do utrzymania wyłącznie dlatego, że Hesse lokalizuje znaczenie w języku. Jednakże relacje logiczne zachodzą pomiędzy znaczeniami, nie pomiędzy słowami. Jeśli nośnikiem znaczenia jest raczej użytkownik języka niż sam język, to może ono funkcjonować jako stabilny przedmiot w operacjach logicznych pod warunkiem, że intencja użytkownika jest jednoznaczna. Relacje wynikania oraz znaczenia dopuszczałyby zatem wzajemne oddziaływanie treści religii i nauki.

Na koniec wspomnę jeszcze o trzech innych kwestiach. Po pierwsze, zastosowanie koncepcji poziomów organizacji do natury ludzkiej przynosi korzyść w postaci rozróżnienia wiary, poznania oraz wyobrażeń jako nieredukowalnych sposobów funkcjonowania. Do wyjaśnienia pozostaje, jak mielibyśmy rozpo-

\footnotetext{
${ }^{13}$ Por. Hans JonAS, Zasada odpowiedzialności. Etyka dla cywilizacji technologicznej, przeł. Marek Klimowicz, Wydawnictwo Platan, Kraków 1996, s. 92-93. Jonas przypisuje etyczne zubożenie zjawisk przyrodniczych - jak w przypadku błędu naturalistycznego, który uznaje się za błąd właśnie ze względu na to zubożenie — rozwinięciu się koncepcji bytu, która wyklucza znaczenie. Wynika z tego, że koncepcja bytu, która inkorporuje znaczenie, uznałaby istnienie relacji logicznych oraz semantycznych pomiędzy religią a nauką za coś naturalnego.

${ }^{14}$ Hesse, „The Cognitive Claims of Metaphor...”, s. 1.
} 
znawać te nieredukowalne sposoby funkcjonowania. Po drugie, skupiłem uwagę na oddziaływaniu pomiędzy poznaniem a wyobraźnią oraz na tym, w jaki sposób objaśniają one wzajemne oddziaływanie treści religii i nauki. Wyzwanie polega na wyjaśnieniu, jak wiara oddziałuje z poznaniem lub jak poznanie oddziałuje z wyobraźnią. Być może istnieją jeszcze inne konsekwencje dla oddziaływania między religią a nauką. Wreszcie, w omówionych przykładach metaforycznego przeniesienia takie pojęcia jak „stałość” i ,jedność” nie mają charakteru wyłącznie chrześcijańskiego. Przeniesienie znaczenia swoiście chrześcijańskiego wymagałoby bowiem chrześcijańskiego kontekstu.

Jitse M. van der Meer

The Concept of Human Nature in Science and Theology

\section{Summary}

Many Christians separate religion and science for fear that changes in scientific understanding of nature will force changes in religious belief. To alleviate this fear, many Christians define interaction out of existence by reducing its complexity. For instance, science is often reduced to a logical domain of knowledge characterized by its propositions. Religion is taken to be a non-logical way of human functioning known as trusting characterized by feelings. According to the doctrine of logical types there can be logical relations only between logical domains of knowledge. Therefore, there can be no logical relations between religion and science if religion is taken to be a non-logical way of human functioning known as trusting, and science as a logical way of functioning. Yet one logical relation has been identified, and religion and science have affected each other's content in other ways. These ways can be accounted for, I propose, by replacing one-dimensional logical conceptions of knowing such as the syntactic and semantic views of theory with a multi-dimensional conception of knowing.

I begin my alternative account of the interaction between religion and science by grounding it in human nature because only people stand in relation to both God and nature. Next, I distinguish a range of irreducible ways of human functioning which correspond with dimensions of a person's relation with God and with nature. Using two of these dimensions as an example - trusting and knowing - I show that interaction between religion and science is seen to be between (a) trust in God (faith) and beliefs about God (theology), (b) trust in God (faith) and beliefs about the world (science) and (c) beliefs about God (theology) and beliefs about the world (science). I argue that there can be interaction between each and every way of human functioning by means of the metaphoric transfer of meaning, for instance, between each of the pairs of functioning just listed. 
Keywords: religion and science, theology and science, human nature, metaphor.

Słowa kluczowe: religia a nauka, teologia a nauka, natura ludzka, metafora. 